All rights reserved

\title{
Bertrand-Edgeworth equilibrium in a cash-in-advance economy
}

\author{
By Erdem Başçı ${ }^{*}$ and Ismail Saglam† \\ ${ }^{\star}$ Department of Economics, Bilkent University, Bilkent, Ankara 06533, Turkey; \\ e-mail: basci@bilkent.edu.tr \\ $\dagger$ Department of Economics, Bogazici University, Bebek, Istanbul 34342, Turkey; \\ e-mail: saglamis@boun.edu.tr
}

\begin{abstract}
This paper is about price and wage competition in a dynamic general equilibrium model. We consider an equity financed economy where firms need money to finance their input costs. Part of the output is sold for money to be used in the next period as working capital and the remaining part is distributed to owners as real dividends. We first characterize the steady state competitive equilibrium path. Second, we study whether this competitive equilibrium can be supported as a pure strategy Nash equilibrium in price and wage setting games. We prove a positive result for price competition and a negative one for wage competition.
\end{abstract}

\section{Introduction}

This paper is about price and wage competition in a dynamic monetary model. We address the question of whether Walrasian competitive equilibrium can be viewed as a pure strategy Nash equilibrium of a Bertrand-Edgeworth price/wage competition game played by a finite number of firms (i.e. an oligempory). ${ }^{1}$

The problem of justifying the Walrasian price-taking assumption as a result of decentralized price competition is not new. A positive result is obtained when marginal production costs are fixed and there are no capacity constraints (Bertrand, 1883). In this case, the unique Nash equilibrium is to equate price to marginal cost by all the firms. Neither cutting nor raising price pays off since rival firms are ready to produce unlimited amounts to serve all customers. However, if there are capacity constraints or if marginal costs are increasing with sales, the basic problem is that Nash equilibrium fails to exist (Edgeworth, 1897; Arrow, 1959; Shubik, 1959; Allen and Hellwig, 1986a, 1986b; Vives, 1986; Benassy, 1989; Börgers, 1992). The non-existence is mainly due to the incentives to unilaterally raise price above marginal cost since rivals are either unable or unwilling to serve the deviating firm's frustrated customers. Since each firm has such a monopoly power

${ }^{1}$ We thank an anonymous referee for suggesting the use of this technical term, oligempory. The term has first been used by Nichol (1943) to describe price and wage competition among a few players. 
over its own customers, it pays off to act a monopolist when others behave competitively.

Under reputational considerations, like assuming cost of turning away customers, supportability of Walrasian equilibrium as a Nash equilibrium of a BertrandEdgeworth price competition game in static one-shot environments has been well established (see Dixon, 1990, and Dastidar, 1997). This assumption is enough to generate a voluntary reserve supply from the rivals to penalize price increases above the competitive level. ${ }^{2}$ But such a consideration which makes more sense in dynamic environments has not been studied in dynamic general equilibrium settings before.

Our contribution to this literature is as follows. We address the same question in a dynamic general equilibrium setup, first time in the literature. We allow for price competition and wage competition within the same context. We choose to work in the recently popularized factor-cost-in-advance models, where firms' capacity constraints in a given period come from the financial side. In such models it is typical to observe a working capital premium on prices above marginal costs (Fuerst, 1992; Christiano et al., 1997; Barth and Ramey, 2001; Başçı and Saglam, 2003). We ask the question whether such working capital premium would continue to prevail in a non-cooperative model of price (and wage) competition.

In any given period firms choose to sell only part of their product to be used as retained earnings. The remaining part of the output is paid as real dividends to owners. The owners have a strictly concave utility function. Therefore higher sales are costly in terms of foregone current utility but are good in terms of future utility obtainable from higher working capital in the next period. In such a novel setup, the extra voluntary supply above the 'Walrasian' level may be higher than that in the static one shot problem discussed, for example, by Dixon (1990) under the same amount of lump-sum turnaway cost. This makes supportability of price taking equilibrium easier, i.e. with a relatively smaller number of firms, in the dynamic case.

The paper is organized as follows. Section 2 introduces the dynamic monetary economy. Section 3 describes the 'Walrasian' price taking framework for the monetary economy under consideration. Section 4 introduces the Bertrand-Edgeworth competition model associated with our financially constrained production economy and then presents the results. Finally, Section 5 concludes by reflecting on the results and their possible extensions.

\section{The dynamic production economy}

In this section, we concentrate on the equity financed factor-cost-in-advance model of the monetary economy examined in Başçı and Saglam (2003). This is

\footnotetext{
${ }^{2}$ A similar reserve supply appears in equilibria of a discrete price setting game (Dixon, 1993) and of a carefully designed market mechanism (Dixon, 1992), where firms report their prices and 'capacities' simultaneously.
} 
a deterministic and simplistic version of the broader class of limited participation models introduced by Fuerst (1992), where firms face finance constraints in their short term factor payments. In the version we consider, the economy consists of infinitely lived agents and the markets operate via fiat money. There are two types of producer-consumers with constant returns technologies; we distinguish them with the high-tech and low-tech labels, depending on their productivities. To identify the high-tech type agents, we also use the term 'firms' interchangeably. Similarly, for the low-tech types, we use the term 'workers'.

The agents have type-specific initial labor endowments and money holdings and are allowed to produce as well as to transact in the spot labor and good markets under given market prices. They face cash-in-advance constraints in all markets. As an equilibrium concept, it is natural to study the stationary monetary competitive equilibrium (SMCE) in which the production, consumption, trading, and saving decisions are, in each time period, feasible, optimal, and time invariant under the stationary competitive prices. Başçı and Saglam (2003) show that the sequencing of the markets matters for the equilibrium of such a financially constrained monetary economy. In the case where the good market opens before the labor market, SMCE exhibits the well celebrated equality of real wage and marginal product of labor and equivalently the equality of price and marginal cost. However, in the labor market first' case the equilibrium real wage is found to be below the marginal product of labor as a consequence of the cash-in-advance constraints imposed in the labor market, and therefore firms (the high-tech agents) obtain positive profits as compensation of holding working capital.

Here, we focus on SMCE of the 'labor market first' case, to address the question as to whether monetary competitive equilibrium with positive working capital compensation can be supported as an equilibrium of a genuine model of price competition. We deal with Bertrand-Edgeworth model since firms have endogeneous capacity constraints resulting from finance constraints in their labor market transactions.

The economy involves two commodities at each time $t$, labor and a non-storable consumption good, apple. There are two types of agents indexed by $i=1,2$. There exist finite numbers, $N_{1}$ and $N_{2}$, of the first and second types of agents. We assume $N_{1}, N_{2} \geqslant 2$. Let $\mathcal{N}_{i}=\left(1, \ldots, N_{i}\right)$ be the set of agents of type $i$. Neither of the types value leisure, and their preferences over the lifetime consumption are in the same additively separable form $\sum_{t=0}^{\infty} \beta_{i}^{t} U_{i j}\left(c_{i j t}\right)$, for all $j \in \mathcal{N}_{i}$ of type $i$. Here, $\beta_{i} \in(0,1)$ is the common discount factor for all agents of type $i, c_{i j t}$ the apple consumption and $U_{i j}($.$) the instantaneous utility function of agent j$ of type $i$. We assume that $U_{i j}$ is twice continuously differentiable, $U_{i j}^{\prime}()>0,. U_{i j}^{\prime \prime}()<$.0 and $U_{i j}(0)=0$ for all $j \in \mathcal{N}_{i}$ of type $i$.

Each agent of type 1 has a labor endowment $\bar{L}_{1}>0$ whereas each agent of type 2 has a labor endowment $\bar{L}_{2}=0$. All agents of type $i$ have a constant returns technology $f_{i}(L)=\gamma_{i} L$ to convert labor into apples with marginal product of labor equal to $\gamma_{i}$. We assume that type 2 agents own a superior know-how, and let $\gamma_{2}=\gamma>1$ and $\gamma_{1}=1$ without loss of generality. Since $\gamma>1$, we identify type 1 
and type 2 agents by the 'low-tech' and the 'high-tech' labels, respectively. Other than these production possibilities, there are no endowment of apples.

We also assume that agent $j \in \mathcal{N}_{i}$ of type $i$ is endowed with the money balance, $M_{i j, 0}=\bar{M}_{i}$ at time zero. For obvious reasons, we require that $\bar{M}_{1}+\bar{M}_{2}>0$, i.e. the total quantity of money initially held is strictly positive. Moreover, there is no further monetary intervention to the economy; so the total money stock remains constant.

We denote and describe a society by $\mathcal{S}=\left\langle N_{i}, \bar{L}_{i}, \bar{M}_{i}, U_{i j}, \beta_{i}, f_{i}\right| i=1,2$ and $\left.j \in \mathcal{N}_{i}\right\rangle$, provided that all parameters listed obey the stated assumptions above.

Now given a society, a trade institution for that society is the description of choice variables for each type of agents, constraints on the given choice variables determined by given prices, and a feasibility requirement (market clearing) for the collective choices of agents. The choice variables of agent $j$ of type $i$ for the period $t$ are listed below.

$c_{i j t}:$ cosumption,

$L_{i j t}$ : labor demand $((+)$ demand, (-) supply),

$Q_{i j t}$ : apple demand ((+) demand, (-) supply),

$M_{i j, t}:$ money balances in the beginning of the period,

$w_{i j t}$ : nominal wage rate,

$p_{i j t}:$ nominal apple price.

The timing of transactions is as follows: Agent $j$ of type $i$ starts period $t$ with an initial money balance $M_{i j, t}$. First the labor market opens where labor can be purchased at the market wages $\left\langle w_{i j t}\right| i \in\{1,2\}$ and $\left.j \in \mathcal{N}_{i}\right\rangle$. All wage bills must have been paid before the good market opens. Then apple production takes place with the purchased and unsold labor. After the harvest of apples, the good market opens where apple can be purchased at the market prices $\left\langle p_{i j t}\right| i \in\{1,2\}$ and $\left.j \in \mathcal{N}_{i}\right\rangle$. These transactions will determine the next period's money balance of each agent.

\section{Walrasian framework}

In this section, we assume that all agents take the wage and price as given. Let $w_{t}$ and $p_{t}$ be the market wage and apple price respectively, at time $t$. The agents assume that they can buy and sell any amount of any commodity at the given prices and wages, provided that they meet their sequence of budget constraints.

Given the endowment structure assumed in the previous section and a sequence of strictly positive prices $\left\langle w_{t}, p_{t}\right\rangle_{t=0}^{\infty}$, we can write the lifetime utility maximization problem, $\left(P_{i j}\right)$, of agent $j$ of type $i$ as follows

$$
\left(P_{i j}\right) \quad \max \sum_{t=0}^{\infty} \beta_{i}^{t} U_{i j}\left(c_{i j t}\right)
$$

subject to, for all $t=0,1, \ldots$,

$$
c_{i j t}=f_{i}\left(\bar{L}_{i}+L_{i j t}\right)+q_{i j t}
$$




$$
\begin{gathered}
-\bar{L}_{i} \leqslant L_{i j t} \leqslant \frac{M_{i j, t}}{w_{t}} \\
-f_{i}\left(\bar{L}_{i}+L_{i j t}\right) \leqslant q_{i j t} \leqslant \frac{M_{i j, t}-w_{t} L_{i j t}}{p_{t}} \\
M_{i j, t+1}=M_{i j, t}-w_{t} L_{i j t}-p_{t} q_{i j t} \\
M_{i j, t+1} \geqslant 0
\end{gathered}
$$

and $M_{i j, 0}=\bar{M}_{i} \geqslant 0$ given.

The upper bound on labor purchases, $L_{i j t}$, in (2) comes from the cash-in-advance requirement and the assumption that the labor market opens first. The lower bound shows the maximum amount of labor that agent $j$ of type $i$ can sell. The constraints on apple purchases, (3), need to be read similarly, taking into account that the payments/receipts in the apple market come after those in the labor market.

We call the trade institution that lets the labor market open first financially constrained by virtue of the fact that a producer is restricted in its labor purchases with the amount of money he holds in the beginning of each period. By a financially constrained production economy we mean a society $\mathcal{S}$ operating under a financially constrained trade institution, and denote it by $\mathcal{F C E}$. Now we can define our equilibrium concepts.

\subsection{The monetary competitive equilibrium}

We say that $\left\langle p_{t}, w_{t}, c_{i j t}, L_{i j t}, q_{i j t}, M_{i j, t+1}\right| i \in\{1,2\}$ and $\left.j \in \mathcal{N}_{i}\right\rangle_{t=0}^{\infty}$ is a monetary competitive equilibrium (MCE) of the financially constrained production economy $\mathcal{F C E}$, if $w_{t}, p_{t}>0$ for all $t$, and

(i) $\left\langle c_{i j t}, L_{i j t}, q_{i j t}, M_{i j, t+1}\right| i \in\{1,2\}$ and $\left.j \in \mathcal{N}_{i}\right\rangle_{t=0}^{\infty}$ solves $\left(P_{i j}\right)$,

(ii) $\sum_{i=1}^{2} \sum_{j=1}^{N_{i}} L_{i j t}=0$ and $\sum_{i=1}^{2} \sum_{j=1}^{N_{i}} q_{i j t}=0$ for all $t$,

(iii) $\sum_{i=1}^{2} \sum_{j=1}^{N_{i}} M_{i j, t}=N_{1} \bar{M}_{1}+N_{2} \bar{M}_{2}$ for all $t$.

The first condition is the lifetime utility maximization under perfect foresight of future prices and price taking behavior. The second states the clearing of commodity market. The third is the money market clearing.

In this paper, we focus on the following monetary competitive equilibrium.

\subsection{The stationary monetary competitive equilibrium}

A stationary monetary competitive equilibrium (SMCE) of the financially constrained economy $\mathcal{F C E}$, is a MCE where the prices, wages, consumption levels, demands, supplies, money holdings are all constant over time. These constant values will be represented by the list $\left\langle p^{*}, w^{*}, c_{i j}^{*}, L_{i j}^{*}, q_{i j}^{*}, M_{i j}^{*}\right| i \in\{1,2\}$ and $\left.j \in \mathcal{N}_{i}\right\rangle$.

The above definition can also be called a steady state equilibrium. It should be noted that the initial money distribution over the two types matters for the 
existence of a stationary equilibrium. So, in looking for SMCE, one should search not only for prices, but also for initial money distributions $\left(\bar{M}_{1}, \bar{M}_{2}\right)$ over types that will yield an allocation consistent with stationarity as well as conditions (i)-(iii) of monetary competitive equilibrium.

It is not very difficult to establish that SMCE exists only if $\left(\bar{M}_{1}, \bar{M}_{2}\right)=(0, M)$, where $M$ denotes the quantity of nominal money stock per firm. Since all prices are constant over time, if a worker-type agent was to start with a positive initial money balance, she would bring it down to zero in finite time. ${ }^{3}$ Using this reasoning, the following proposition characterizes the set of SMCE over the parameter space of $\left(\beta_{2}, \gamma\right)$.

Proposition 1 (Başçı and Saglam, 2003) Stationary monetary competitive equilibria (SMCE) of a financially constrained economy $\mathcal{F C E}$ exists if and only if $\left(\bar{M}_{1}, \bar{M}_{2}\right)=(0, M)$ and $\beta_{2} \gamma \geqslant 1$. Moreover, the set of SMCE is characterized by (6)-(15):

$$
\begin{aligned}
& w^{*}= \begin{cases}N_{2} M /\left(N_{1} \bar{L}_{1}\right) & \text { if } \beta_{2} \gamma>1 \\
\bar{w} \in\left[N_{2} M /\left(N_{1} \bar{L}_{1}\right), \infty\right) & \text { if } \beta_{2} \gamma=1\end{cases} \\
& p^{*}=\frac{w^{*}}{\beta_{2} \gamma} \\
& L_{1 j}^{*}=-N_{2} M /\left(N_{1} w^{*}\right), \quad j \in \mathcal{N}_{1} \\
& L_{2 j}^{*}=M / w^{*}, \quad j \in \mathcal{N}_{2} \\
& q_{1 j}^{*}=-\frac{w^{*}}{p^{*}} L_{1 j}^{*}, \quad j \in \mathcal{N}_{1} \\
& q_{2 j}^{*}=-\frac{w^{*}}{p^{*}} L_{2 j}^{*}, \quad j \in \mathcal{N}_{2} \\
& c_{1 j}^{*}=\bar{L}_{1}+\left(1-\frac{w^{*}}{p^{*}}\right) L_{1 j}^{*}, \quad j \in \mathcal{N}_{1} \\
& c_{2 j}^{*}=\left(\gamma-\frac{w^{*}}{p^{*}}\right) L_{2 j}^{*}, \quad j \in \mathcal{N}_{2} \\
& M_{1 j}^{*}=0, \quad j \in \mathcal{N}_{1} \\
& M_{2 j}^{*}=M, \quad j \in \mathcal{N}_{2}
\end{aligned}
$$

It is immediate to observe that whenever SMCE exists, the real wage is strictly below the marginal product of labor in the 'high-tech' production plant, and equals $w^{*} / p^{*}=\beta_{2} \gamma<\gamma$. This is due to the fact that money earned by the producers can only be spent in the following period. If $\beta_{2} \gamma>1$ then SMCE exists and is unique. If $\beta_{2} \gamma=1$ then there exists a continuum of SMCE that can be Pareto ranked, and SMCE does not exist if $\beta_{2} \gamma<1$.

\footnotetext{
${ }^{3}$ A sketch of the proof of this statement is given by Stokey and Lucas (1989, Exercise 5.17).
} 
The detailed proof is given in Baş̧ı and Saglam (2003). Here we will discuss the nature of the equilibrium with special interest on the firm owner's problem.

Provided that price is at least as high as marginal production cost, the cash-inadvance constraint (2) binds the firm owner at all times, so that the lifetime welfare of the competitive firm owner, $\mathcal{W}_{c}$ can be rewritten as

$$
\mathcal{W}_{c}\left(\left\{q_{t}^{s}\right\}_{t=0}^{\infty}\right)=U\left(f\left(\frac{M_{0}}{w^{*}}\right)-q_{0}^{s}\right)+\sum_{t=1}^{\infty} \beta^{t} U\left(f\left(\frac{p^{*} q_{t-1}^{s}}{w^{*}}\right)-q_{t}^{s}\right)
$$

where indices of $U$ and $f$ are dropped and $q_{t}^{s}$ is used, for notational simplicity, to denote the quantity supplied by one of the firms. The feasible set of supply sequences for the firm owner, $\Gamma$ depends on the initial money stock, as well as the competitive wage and competitive price and is given by

$$
\begin{aligned}
\Gamma\left(M_{0}, w^{*}, p^{*}\right)= & \left\{q_{t}^{s}, t \geqslant 0 \mid q_{0}^{s} \in\left[0, f\left(M_{0} / w^{*}\right)\right],\right. \\
& \left.q_{t}^{s} \in\left[0, f\left(p^{*} q_{t-1}^{s} / w^{*}\right)\right] \text { for } t \geqslant 1\right\} .
\end{aligned}
$$

Then the firm owner's problem becomes that of maximizing

$$
\mathcal{W}_{c}\left(\left\{q_{t}^{s}\right\}_{t=0}^{\infty}\right)
$$

subject to

$$
\left\{q_{t}^{s}\right\}_{t=0}^{\infty} \in \Gamma\left(M_{0}, w^{*}, p^{*}\right)
$$

Let $v_{c}\left(M_{0}\right)$ denote the optimal lifetime utility from the initial working capital $M_{0}$, under the competitive price taking assumption. Also let the feasible set of supplies, $q^{s}$, in current period be denoted by $\Gamma_{c}\left(M_{0}\right)=\left[0, f\left(M_{0} / w^{*}\right)\right]$. The Bellman equation for a price taking firm can then be written as

$$
v_{c}\left(M_{0}\right)=\max _{q^{s} \in \Gamma_{c}\left(M_{0}\right)}\left\{U\left(f\left(M_{0} / w^{*}\right)-q^{s}\right)+\beta v_{c}\left(p^{*} q^{s}\right)\right\}
$$

for all $M_{0} \geqslant 0$.

The first term on the right hand side gives the current utility from consumption and the second term stands for the discounted continuation utility from next period's working capital. Under our assumptions about the utility function and the constraint set, the existence and uniqueness of a value function $v_{c}: \mathbb{R}_{+} \rightarrow \mathbb{R}$ that satisfies the Bellman equation (18) is well established (e.g. See for example Theorem 4.6 in Stokey and Lucas, 1989).

A combination of the first order condition of the maximization problem in (18) and the envelope condition (Benveniste-Scheinkman condition, Theorem 4.10 in 
Stokey and Lucas, 1989) produces the traditional Euler equations for the firm owner, given by

$$
U^{\prime}\left(c_{t}\right)-\beta_{2} U^{\prime}\left(c_{t+1}\right) \frac{p^{*}}{w^{*}} \gamma=0
$$

for each $t$. Since labor supply, output, and liquidity constrained workers' consumption are all constant over time, $c_{t}$, consumption of firm owners has to be constant over time as well. Cancelling out the marginal utilities in (19) results in (7) or

$$
p^{*}=\frac{w^{*}}{\beta_{2} \gamma}
$$

This equation tells that in a steady state price taking equilibrium, the prices carry a working capital premium over marginal production cost. The working capital premium can be expressed as

$$
p^{*} / M C=\frac{1}{\beta_{2}}
$$

This premium arises because the firms can spend their sales revenue to convert it to utilities only in the next period. Since the firms abstain from selling all of their output in the current period, quantity supplied is restricted; so that the usual

$$
p^{*}=M C
$$

condition observed in static models or in models with no finance constraints on firms fails to hold in this dynamic cash-in-advance economy. ${ }^{4}$

The equilibrium consumption of firm owners can be obtained by inserting (20) and (9) into (13) as

$$
c_{2 j}^{*}=\left(1-\beta_{2}\right) f\left(M / w^{*}\right), \quad j \in \mathcal{N}_{2}
$$

It is seen that the per period consumption (hence the life-time utility) of any producer is positive in equilibrium. From (6) it then follows that whenever $w^{*}$ is determined endogenously, i.e., the $\beta \gamma>1$ case, each firm's per period consumption is positive if and only if the number of firms per workers, $N_{2} / N_{1}$, is finite. However, the aggregate consumption of the firms in the market is independent of their number and equals $\left(1-\beta_{2}\right) \gamma \sum_{j \in \mathcal{N}_{1}}\left(L_{1 j}^{*}\right)$. On the other hand workers, overall, consume the fraction $\beta_{2}$ of the total output produced in the high-tech plants while firm owners consume whatever remains of output. It should also be noted that, the lower the time preference of firms $\left(\beta_{2}\right)$ is, the higher is the working capital premium and hence their total consumption in equilibrium.

${ }^{4}$ Fuerst (1992) shows in a similar cash-in-advance model where firms borrow funds to finance their wage bill that the working capital premium is linked to nominal short term interest rate, $r$, via $p^{*} / M C=(1+r)$. Başçı and Saglam (2003) show that $p^{*}=M C$ prevails only when firms are able to sell their goods in advance to consumers. 


\section{Bertrand-Edgeworth competition}

In this section we characterize the conditions under which every stationary monetary competitive equilibrium of our economy is a Nash equilibrium of a Bertrand-Edgeworth model of competition.

We would like to discuss first why we deal with Bertrand-Edgeworth model which assumes finite capacities. The firms in our economy are endowed with constant returns technologies so that they have no capacity constraints coming from the technology side. However, inability to meet demand may arise due to cash-in-advance constraints in the factor markets. Since the labor market opens before the good market, production level of each firm is determined before firms enter competition in the good market. Therefore, a firm, which aims to undercut its rivals in the good market by reducing its price in some period, may not cover the market demand unless it has just produced a sufficiently large quantity of apples. A similar situation arises when firms compete in the labor market. The winning firm of the wage competition may not be able to hire the amount of labor required to meet the good market demand, since firms face cash-in-advance constraints and have finite money holdings.

We assume that all agents in the economy have a recursive reasoning. They believe competition may occur only in the current period while they expect prices and wages to be in SMCE from the next period onwards. In addition, we restrict ourselves to the case where price and/or wage can be set by firm owners only. Workers are assumed to be both price and wage takers.

If firm owners charge different prices in any time period, consumers start buying from the firm(s) with the lowest price offer. Following the 'equal shares' rationing rule, considered for example by Deneckere and Kovenock (1992), we assume that consumers with equal demands receive equal shares of the output available whenever excess demand exists at a certain price. With their residual money, consumers continue to buy from the lowest of the remaining price offers.

Likewise, workers first supply their labor to the firm(s) that bid the highest wage. Firms with the same wage offerings will employ equal shares of labor supply, and workers with the same supply share the market demand equally. If workers have excess labor supply, they offer it to the firm(s) with the second highest wage, and so on.

Products in the economy are homogeneous and firms have no relative advantage with respect to each other in marketing their products.

These last four assumptions are made to ensure that all firms using the same price (wage) strategy will face the same commodity demand (labor supply).

\subsection{Turnaway costs and voluntary excess supply}

In case of price competition, we allow for the presence of a lump sum disutility, $d_{c} \geqslant 0$, from turning down customers. Given other firms' price offers, our firm faces a residual demand as a function of its own price in the current period. In case our 
firm chooses not to fulfill all of that demand, there will be a fixed disutility of $d_{c}$ which is subtracted from the lifetime utility of the firm owner.

For a given level of turnaway cost, $d_{c}$, the first question is finding the maximum amount of excess supply, over the competitive level $q^{*}$, that a given firm would be willing to provide under the competitive (SMCE) price level $p^{*}$ to its customers. We denote this extra supply by $q^{e}\left(d_{c}\right)$ to emphasize its depencence on the turnaway cost.

If a firm were to sell the total amount $q^{*}+q^{e}$ in the current period, the next period's beginning of period working capital would become $p^{*}\left(q^{*}+q^{e}\right)$. Therefore the implicit function defining $q^{e}$ for any given value of $d_{c}$ can be expressed as the indifference relation

$$
v_{c}\left(M_{0}\right)-d_{c}=U\left(f\left(\frac{M_{0}}{w^{*}}\right)-\left(q^{*}+q^{e}\right)\right)+\beta v_{c}\left(p^{*}\left(q^{*}+q^{e}\right)\right)
$$

Here, $v$ is the optimal value function, which gives the maximum lifetime utility as a function of initial working capital under competitive prices $\left(p^{*}, w^{*}\right)$. The left hand side shows the lifetime utility from declining to sell above the competitive level and the right hand side shows the utility from selling $q^{e}$ units more than the optimal $q^{*}$ units in the current period and acting optimally after $t=1$ with initial money $p^{*}\left(q^{*}+q^{e}\right)$.

It is worthwhile to note that a firm may accept to sell above the competitive output $q^{*}$ only if the reputation cost $d_{c}$ is strictly positive. Besides, there is a finite treshold for $d_{c}$ above which the firm never turns down customers unless demand exceeds the total output produced. This cost treshold, $\bar{d}_{c}$, can be obtained by inserting $q^{*}+q^{e}=f\left(M_{0} / w^{*}\right)$ into (23) and solving for

$$
\bar{d}_{c}=v_{c}\left(M_{0}\right)-\beta v_{c}\left(p^{*} f\left(\frac{M_{0}}{w^{*}}\right)\right)
$$

For reputation costs above the treshold $\left(d_{c} \geqslant \bar{d}_{c}\right)$, the firm sets $q^{e}=(1-\beta) \times$ $f\left(M_{0} / w^{*}\right)$ and supplies all of its output unless it faces an excessive demand.

Lemma 1 Equation (23) uniquely determines excess supply, $q^{e}$, as a function of turnaway cost, $d_{c}$. Moreover $q^{e}\left(d_{c}\right)$ is a strictly increasing function of $d_{c}$ over the interval $\left(0, \bar{d}_{c}\right)$ with $q^{e}(0)=0$.

Proof Consider the Bellmans equation

$$
v_{c}\left(M_{0}\right)=\max _{q^{s} \in\left[0, f\left(M_{0} / w^{*}\right)\right]}\left\{U\left(f\left(M_{0} / w^{*}\right)-q^{s}\right)+\beta v_{c} p^{*}\left(q^{s}\right)\right\}
$$

for all $M_{0} \geqslant 0$.

By the strict concavity of the utility function, we know that the value function, $v_{c}$ is strictly concave as well (Stokey and Lucas, 1989, theorem 4.8). Then the sum of the current utility $U$ and the continuation utility $\beta v_{c}$ is also strictly concave in $q^{s}$. 
Therefore above the optimal quantity supplied, $q^{*}$, the right hand side of eq. (23) is strictly decreasing. This shows the existence of a unique $q^{e}$ for any given $d_{c} \in\left(0, \bar{d}_{c}\right)$, with $q^{e}(0)=0$ and the fact that $d q^{e} / d d_{c}>0$ over the set $\left(0, \bar{d}_{c}\right)$.

Therefore, a firm is willing to meet its demand if and only if $q^{d} \leqslant q^{*}+q^{e}\left(d_{c}\right)$. For excessively high demands, i.e. $q^{d}>q^{*}+q^{e}\left(d_{c}\right)$, the firm chooses to supply the competitive level $q^{*}$ despite the turnaway cost.

\subsection{Nash equilibrium of price competition game}

Let $p_{j}$ and $w_{j}$ be respectively the output price and the nominal wage rate set by firm $j \in \mathcal{N}_{2}$ in the current period. Also let $(\mathbf{p}, \mathbf{w}) \equiv\left\langle p_{j}, w_{j}\right\rangle_{j \in \mathcal{N}_{2}}$ denote the vector of wages and prices charged by the firms in the economy. We define $\left(\mathbf{p}_{-\mathbf{j}}, \mathbf{w}\right) \equiv$ $\left\langle p_{i}, \mathbf{w}\right\rangle_{i \neq j}$, and $\left(\mathbf{p}, \mathbf{w}_{-\mathbf{j}}\right) \equiv\left\langle\mathbf{p}, w_{i}\right\rangle_{i \neq j}$, for notational convenience. Moreover, $\left(\mathbf{p}^{*}, \mathbf{w}^{*}\right) \equiv$ $\left\langle p^{*}, w^{*}\right\rangle_{j \in \mathcal{N}_{2}}$ denotes $2 \times N_{2}$-tuple of SMCE prices and wages.

Let $\bar{U}_{2 j}(\mathrm{p}, \mathrm{w})$ denote the lifetime utility of firm owner $j$ when the prices and wages are given by $(\mathbf{p}, \mathbf{w})$ in the current period.

We say that $(\mathbf{p}, \mathbf{w})$ is a Nash equilibrium of the Bertrand-Edgeworth price competition game if for all $j \in \mathcal{N}_{2}$

$$
\bar{U}_{2 j}(\mathbf{p}, \mathbf{w}) \geqslant \bar{U}_{2 j}\left(\hat{p}_{j}, \mathbf{p}_{-\mathbf{j}}, \mathbf{w}\right) \quad \text { for all } \hat{p}_{j} \geqslant 0
$$

Proposition 2 Let the turnaway cost $d_{c}$ be strictly positive. Assume that all firms are wage takers. If $N_{2}-1 \geqslant q^{*} / q^{e}\left(d_{c}\right)$, then the SMCE is also a Nash equilibrium of the Bertrand-Edgeworth price competition game.

The proof is developed in two steps. First Lemma 2 below shows that for any given level of turnaway cost, cutting the price below the SMCE level cannot be optimal. Then the proof of Proposition 2 shows that raising the price above the SMCE level is not optimal under strictly positive turnaway costs and sufficiently high number of competitors.

Lemma 2 Let turnaway cost $d_{c} \geqslant 0$ be given. Undercutting the price $p_{0}$ below the SMCE level $p^{*}$ does not increase the lifetime utility of a firm owner if all other firms set their prices at $p^{*}$.

The detailed proof of Lemma 2 is given at the Appendix. The intuition is that since the markup in the price over marginal cost is the compensation for keeping money as working capital, the firms do not choose to expand output under competitive prices, even though they have an opportunity to sell more. Hence there is no point in cutting the price below the SMCE level in order to sell more than the competitive quantity supplied.

Proof of Proposition 2 Undercutting the SMCE price is not optimal by Lemma 2. Now suppose our firm raises the price to $p_{j}>p^{*}$. The demand of our firm's customers, $q^{*}$ is first channeled to the rival $N_{2}-1$ firms who have posted $p^{*}$. 
Each one of the rivals will meet this extra demand, by Lemma 1, if and only if

$$
\frac{q^{*}}{N_{2}-1} \leqslant q^{e}\left(d_{c}\right)
$$

or equivalently

$$
N_{2}-1 \geqslant \frac{q^{*}}{q^{e}\left(d_{c}\right)}
$$

which may hold for a finite number of firms, $N_{2}$, only if $d_{c}>0$.

Proposition 2 shows that for any level of nonzero reputation cost, there exists a minimal finite number of firms that can obtain SMCE outcome as the Nash equilibirum of a Bertrand-Edgeworth game they play. The proposition also shows that for an economy with less than $1 /\left(1-\beta_{2}\right)$ firms, there is the possibility that firms benefit from selling above $p^{*}$ in the current period, since they may continue selling to at least some of their customers. This observation jointly follows from

$$
q^{e}\left(d_{c}\right) \leqslant\left(1-\beta_{2}\right) q^{*}
$$

and (25).

An immediate corollary of Proposition 2 is that markets with 'very myopic' producers (i.e. firms with common time preference $\beta_{2}$ very close to zero), price competition under Bertrand-Edgeworth model may lead to SMCE if the number of firms is at least two, i.e., 'two' is enough for competition. ${ }^{5}$ Another direct corollary would state that in a market involving arbitrarily large number of firms the market share of any single firm becomes so small that the aggregate supply of any $N_{2}-1$ of $\mathrm{N}_{2}$ firms can cover the market demand unless $\beta_{2}$ is equal to one, implying that no firm in a 'large' economy has an incentive to deviate from SMCE.

In static Bertrand-Edgeworth models, the reason for the failure of a competitive equilibrium to be supported as a pure strategy Nash equilibrium is the presence of an incentive to increase the price above the competitive equilibrium level. In our dynamic model, likewise, we have showed that price cutting is never optimal. So if SMCE ever fails to be supported as a Nash equilibrium in the price competition game, it must be due to the profitability of increasing the price. And as the number of firms increase, the incentive to increase the price tends to dissapear.

\subsection{Nash equilibrium of wage and price competition game}

In this section we allow for wage competition as well as price competition, i.e. the case of oligempory. We say that $(\mathbf{p}, \mathbf{w})$ is a Nash equilibrium of the BertrandEdgeworth price and wage competition game if for all $j \in \mathcal{N}_{2}$

$$
\bar{U}_{2 j}(\mathbf{p}, \mathbf{w}) \geqslant \bar{U}_{2 j}\left(\hat{p}_{j}, \hat{w}_{j}, \mathbf{p}_{-\mathbf{j}}, \mathbf{w}_{-\mathbf{j}}\right) \quad \text { for all } \hat{p}_{j}, \hat{w}_{j} \geqslant 0
$$

${ }^{5}$ Of course, too small $\beta_{2}$ may lead to the nonexistence of SMCE itself. However, if labor is assumed to be supplied inelastically at all real wage levels by the workers, then this problem does not appear. 
Proposition 3 Assume that firms compete in wages as well as in prices. Then SMCE is a Nash equilibrium of the Bertrand-Edgeworth price and wage competition game if and only if $w^{*} / p^{*}=1$.

The proof is given at the Appendix. The intuition is that regardless what SMCE wage rate is, no firm can ever become better off by unilaterally raising its nominal wage rate in the current period above the SMCE level due to the cash-in-advance constraints. A profitable deviation from SMCE in (nominal) wage competition may then arise only through wage cutting. When the common time preference of firms, $\beta_{2}$, is equal to their common marginal labor cost of production $1 / \gamma$, SMCE wage rate turns out to be 'one', i.e. the reservation wage of workers. This makes the labor supply infinitely elastic in equilibrium. Therefore, SMCE is a Nash equilibrium when $w^{*} / p^{*}=1$. On the other hand, when $w^{*} / p^{*}=\beta \gamma>1$, the labor supply is inelastic and hence there exists a room for profitable deviations from SMCE by the firms, since in that case workers accept working at any real wage rate in the interval $[1, \beta \gamma)$, and rival firms cannot absorb any extra labor since they are financially constrained.

\section{Concluding remarks}

The literature relating Walrasian equilibria to the Nash equilibria of BertrandEdgeworth models has extensively studied single-shot markets. Shubik (1959) establishes that a Bertrand-Edgeworth model with homogeneous goods has no equilibrium in pure strategies when costs are strictly convex. Benassy (1989) proves that the same result holds in heterogeneous goods markets as well if products are sufficiently similar. Allen and Hellwig (1986a, 1986b) and Vives (1986) show that the mixed strategy Nash equilibria of a Bertrand-Edgeworth model converge in distribution to the Walrasian equilibrium when the number of competitors is very large. More recently, Börgers (1992) finds that the price strategies in a Bertrand-Edgeworth model which survive the iterated elimination of dominant strategies are very close to the Walrasian equilibrium price (i) if any $n-1$ out of $n$ firms in the market have sufficient capacity to cover demand at marginal costs, (ii) if any given total capacity is owned by a large number of very small firms.

In our dynamic model, we established both the existence of a Nash equilibrium in a Bertrand-Edgeworth price competition game and that it coincides with the corresponding price taking equilibrium (SMCE) for a rich set of parameter values. This result, which is obtained under wage taking behavior and hence under sole price competition, hinges upon the presence of a positive residual consumption for the high-tech agents, a factor that has been missing in static formulations.

It is also interesting to observe that when time preferences of firms are very small, SMCE turns out to be Nash equilibrium for every market with at least two firms. At the other extreme, we find that for any given finite number of firms, SMCE is not a Nash equilibrium if time preferences of firms are sufficiently close to one. 
In the case where wage competition is allowed, the usual non-existence problems of Bertrand competition models with capacity constraints show themselves. In this case, there is no counterpart of residual consumption observed under price competition. Therefore, in line with the classical remark of Edgeworth, the only possible case, for supporting a 'Walrasian' equilibrium as a 'Bertrand' equilibrium, would be a highly elastic labor supply. In our model this can happen for parameter values that make the labor supply curve infinitely elastic in equilibrium.

The dynamic nature of the problem is needed to make fiat money valued and to justify, on reputational grounds, the behavioral assumption that a producer aims to meet all the demand it faces at its quoted price, even when it is suboptimal to do so (Dixon, 1990; Dastidar, 1997). Such a reputational story is not described in detail here. Nevertheless, it may be realistic to assume that a seller would in fact suffer more by turning down a small amount of extra customer demand than by fulfilling this extra demand and consuming a bit less in the current period. In fact, the inventory theory models in the literature are built upon this assumption. These models study a trade-off between holding less inventories and turning down less consumers under a stochastic demand process.

Another implicit assumption in our model is the 'recursive reasoning' used by our agents. More precisely, we have assumed that our workers and entrepreneurs take forecasts of future prices as given and take for granted that they will be able to buy and sell any amount that their budget and production technology allow at these prices. In other words, agents act in a Walrasian fashion regarding future prices and only choose current prices. This recursive reasoning, though fulfilled in equilibrium as any 'conjectural equilibrium' would be, is, in fact, a boundedly rational way of thinking. To see this, one may alternatively assume that a single producer regards the whole sequence of prices as a choice variable. Then, especially with a small number of firms, a policy of undercutting the rivals for a sufficiently long period of time and in that way collecting all the cash in the economy, and afterwards following the monopolistic pricing rule to extract the whole social surplus, is definitely a different way of reasoning that may indeed be optimal if all others follow a recursive reasoning. A full strategic analysis where the whole path of future prices are taken as choice variables requires a more sophisticated investigation and is outside the scope of the present paper (see Benoit and Krishna, 1987, for a related partial equilibrium model that incorporates multiple equilibria).

\section{Acknowledgements}

We are thankful to Ahmet Alkan, Huw Dixon, and three anonymous referees of this journal for useful comments and suggestions. We also thank seminar audiences at Bilkent and Koc Universities, and the 2001 North American Summer Meeting of the Econometric Society. The usual disclaimer applies. 


\section{References}

Allen, B. and Hellwig, M. (1986a). 'Bertrand-Edgeworth oligopoly in large markets', Review of Economic Studies, 53, 175-204.

Allen, B. and Hellwig, M. (1986b). 'Price-setting firms and the oligopolistic foundations of perfect competition', American Economic Review, 76, 387-92.

Arrow, K. (1959). 'Toward a theory of price adjustment', in M. Abramovitz et al. (eds), The Allocation of Economic Resources, Stanford University Press, Stanford.

Barth III, M.J. and Ramey, V. (2001). 'The cost channel of monetary transmission', in B.S. Bernanke, and K. Rogoff (eds), NBER Macroeconomics Annual 2001, Cambridge, MA.

Başçı, E. and Saglam, I. (2003). 'On the importance of sequencing of markets in monetary economies’, in M.R. Sertel and S. Koray (eds), Advances in Economic Design, Springer-Verlag, Heidelberg.

Benassy, J.P. (1989). 'Market size and substitutability in imperfect competition: a BertrandEdgeworth-Chamberlin model', Review of Economic Studies, 56, 217-34.

Benoit, J.P. and Krishna, V. (1987). 'Dynamic duopoly: prices and quantities', Review of Economic Studies, 54, 23-35.

Bertrand, J. (1883). 'Book review of Theorié Mathématique de la Richesse Sociale and of Recherches sur les Principes Mathématiques de la Théorie des Richesses', Journal of Savants, 67, 499-508.

Börgers, T. (1992). 'Iterated elimination of dominated strategies in a Bertrand-Edgeworth model', Review of Economic Studies, 59, 163-76.

Christiano, L.J., Eichenbaum, M., and Evans, C.L. (1997). 'Sticky price and limited participation models: a comparison', European Eonomic Review, 41, 1201-49.

Dastidar, K.G. (1995). 'On the existence of pure strategy Bertrand equilibrium', Economic Theory, 5, 19-32.

Dastidar, K.G. (1997). 'Comparing Cournot and Bertrand in a homogeneous product market', Journal of Economic Theory, 75, 205-12.

Deneckere, R.J. and Kovenock, D. (1992). 'Price leadership', Review of Economic Studies, 59, $143-62$.

Dixon, H.D. (1990). 'Bertrand-Edgeworth equilibria when firms avoid turning customers away', Journal of Industrial Economics, 39, 131-46.

Dixon, H.D. (1992). 'The competitive outcome as the equilibrium in an Edgeworthian pricequantity model', Economic Journal, 102, 301-9.

Dixon, H.D. (1993). 'Integer pricing and Bertrand-Edgeworth oligopoly with strictly convex costs: is it worth more than a penny?', Bulletin of Economic Research, 45, 257-68.

Edgeworth, F. (1897). 'La teoria pura del monopolio, Giornale degli Economisti', 40, 13-31 (English translation: the pure theory of monopoly, in Papers Relating to Political Economy, vol. 1, McMillan Press, London, 1925.)

Fuerst, T.S. (1992). 'Liquidity, loanable funds and real activity', Journal of Monetary Economics, 29, 3-24.

Nichol, A.J. (1943). 'Review of A Theoretical Analysis of Imperfect Competition with Special Application to the Agricultural Industries by W.H. Nicholls', Journal of Political Economy, 51, 82-4.

Shubik, M. (1959). Strategy and Market Structure, John Wiley and Sons, New York. 
Stokey, N.L. and Lucas, R.E.J. (with E.C. Presscott) (1989). Recursive Methods in Economic Dynamics, Harvard University Press, Cambridge, MA.

Vives, X. (1986). 'Rationing rules and Bertrand-Edgeworth equilibria in large markets', Economics Letters, 21, 113-6.

\section{Appendix}

\section{Proof of Lemma 2}

First we recall the optimal value function $v_{c}$ for the competitive case. Let the feasible set of supplies, $q^{s}$, in current period be denoted by $\Gamma_{c}\left(M_{0}\right)=$ $\left[0, f\left(M_{0} / w^{*}\right)\right]$. The Bellman equation for a price taking firm can be written as

$$
v_{c}\left(M_{0}\right)=\max _{q^{s} \in \Gamma_{c}\left(M_{0}\right)}\left\{U\left(f\left(M_{0} / w^{*}\right)-q^{s}\right)+\beta v_{c}\left(p^{*} q^{s}\right)\right\}
$$

for all $M_{0} \geqslant 0$.

Next we construct the value function, $v_{B}$, for the Bertrand price setting case. The feasible set of supplies, $q^{s}$, in this case is denoted by $\Gamma_{B}\left(M_{0}, p_{0}\right)=\left[0, \min \left\{f\left(M_{0} / w^{*}\right), q^{d}\left(p_{0}\right)\right\}\right]$, where the quantity demanded of a firm as a function of its own price is given by, $q^{d}\left(p_{0}\right)=q^{*}$ if $p_{0}=p^{*}$ and $q^{d}\left(p_{0}\right)=N_{2} M_{0} / p_{0}$ if $p_{0}<p^{*}$. Note that whenever $p_{0}<p^{*}$, we have $q^{d}\left(p_{0}\right)>q^{*}$. The optimal value function can then be expressed for a given initial money and initial own price as

$$
v_{B}\left(M_{0}, p_{0}\right)=\max _{q^{s} \in \Gamma_{B}\left(M_{0}, p_{0}\right)}\left\{U\left(f\left(M_{0} / w^{*}\right)-q^{s}\right)+\beta v_{c}\left(p_{0} q^{s}\right)\right\}
$$

for all $M_{0} \geqslant 0$ and $p_{0} \geqslant 0$. Here the firm takes all other firms current prices set at the competitive level $p^{*}$ and follows the recursive reasoning by assuming a competitive environment from next period onwards.

Since $q^{d}\left(p_{0}\right)>p^{*}$ whenever $p_{0}<p^{*}$, we have $\Gamma_{B}\left(M_{0}, p_{0}\right) \subset \Gamma_{c}\left(M_{0}\right)$. Moreover, since the value function $v_{c}$ is strictly increasing in the initial money, we have $v_{c}\left(p_{0} q^{s}\right)<v_{c}\left(p^{*} q^{s}\right)$ for all $p_{0}<p^{*}$ and all $q^{s}>0$. Therefore, comparing (28) with (27), we observe

$$
v_{B}\left(M_{0}, p_{0}\right)<v_{c}\left(M_{0}\right)
$$

for all $p_{0}<p^{*}$. On the other hand we also know that

$$
v_{c}\left(M_{0}\right)=v_{B}\left(M_{0}, p^{*}\right)
$$

which follows from the optimality of $q^{*}$ on the set $\Gamma_{c}\left(M_{0}\right)=\left[0, f\left(M_{0} / w^{*}\right)\right]$ in the competitive case and the presence of $q^{*}$ in the set $\Gamma_{B}\left(M_{0}, p^{*}\right)=\left[0, q^{*}\right]$ in the Betrand-Edgeworth case. Combining (29) and (30), we arrive at the conclusion that

$$
v_{B}\left(M_{0}, p_{0}\right)<v_{B}\left(M_{0}, p^{*}\right) \text { for all } p_{0}<p^{*} .
$$

This completes the proof under zero turnaway costs. For $d_{c}>0$ the conclusion does not change since we have

$$
v_{B}\left(M_{0}, p_{0}\right)-d_{c}<v_{B}\left(M_{0}, p^{*}\right)
$$

for all $p_{0}<p^{*}$. 


\section{Proof of Proposition 3}

We first recall from Proposition 1 that SMCE exists if and only if $\beta \gamma \geqslant 1$ and $w^{*} / p^{*}=\beta \gamma$. Now suppose that firm $j$ unilaterally deviates from SMCE wage in period $t=0$. It is obvious that raising the wage rate over the competitive level $w^{*}$ never benefits a firm. With the given level of initial working capital, a higher wage means less people can be employed and less goods can be produced.

Regarding wage cuts, let us consider two cases separately:

(i) $\beta \gamma>1$. In this case, $w^{*} / p^{*}=\beta \gamma>1$ and there exists a unique SMCE, by Proposition 1. Suppose that firm $j$ sets $w_{j} \in\left[p^{*}, w^{*}\right)$. When the remaining $\left(N_{2}-1\right)$ firms stick to $w^{*}$, they will face the whole supply in the labor market; but they can hire no more labor than they do in SMCE, due to the cash-in-advance constraints in the labor market. The deviating firm $j$ will then keep its labor supply, which is perfectly inelastic at $L_{2 j}^{*}$. After the labor market transactions in the current period, firm $j$ will be left with the residual money $M^{r}=M-w_{j} L_{2 j}^{*}$. Suppose that firm owner $j$ spends $\left(N_{2}-1\right) / N_{2} M^{r}$ of this residual money on goods purchases in the current period, while saving $M^{r} / N_{2}$ for the next period. The workers will spend all their wage earnings, $\left(N_{2}-1\right) M_{0}+w_{j} L_{2 j}^{*}$, in the goods market in period $t=0$. Firm $j$ will then obtain $\left(1 / N_{2}\right)$ th of the total sales revenue after the good market closes in the current period. Adding up its sales revenue and the saved part from its residual money, we can calculate the money holding of firm $j$ from $t=1$ onwards as

$$
\frac{1}{N_{2}}\left[\left(N_{2}-1\right) M+w_{j} L_{2 j}^{*}\right]+\frac{M^{r}}{N_{2}}=M
$$

which implies that every other firm will continue to hold $M$ as well, so SMCE prices are still feasible after the current period. The lifetime utility of firm $j$ can then be written as

$$
\begin{aligned}
\bar{U}_{2 j}\left(p^{*}, w_{j}, \mathbf{p}_{-j}^{*}, \mathbf{w}_{-j}^{*}\right) & =U_{2 j}\left(f_{2}\left(L_{2 j}^{*}\right)-\frac{\left(N_{2}-1\right) M+w_{j} L_{2 j}^{*}}{N_{2} p^{*}}+M^{r} \frac{N_{2}-1}{N_{2} p^{*}}\right)+\sum_{t=1}^{\infty} \beta_{2}^{t} U_{2, j}\left(c_{2 j}^{*}\right) \\
& =U_{2 j}\left(f_{2}\left(L_{2 j}^{*}\right)-\frac{w_{j} L_{2 j}^{*}}{p^{*}}\right)+\frac{\beta_{2}}{1-\beta_{2}} U_{2, j}\left(c_{2 j}^{*}\right) \\
& =U_{2 j}\left(f_{2}\left(L_{2 j}^{*}\right)\left(1-\beta_{2} \frac{w_{j}}{w^{*}}\right)\right)+\frac{\beta_{2}}{1-\beta_{2}} U_{2, j}\left(c_{2 j}^{*}\right) \\
& >U_{2 j} c_{2 j}^{*}+\frac{\beta_{2}}{1-\beta_{2}} U_{2, j}\left(c_{2 j}^{*}\right) \\
& =\bar{U}_{2 j}\left(\mathbf{p}^{*}, \mathbf{w}^{*}\right)
\end{aligned}
$$

Thus, for any given $\beta_{2}$ satisfying $\beta_{2} \gamma>1$, there exists $w_{j}<w^{*}$, satisfying $w_{j} / p^{*} \in\left[1, \beta_{2} \gamma\right)$ so that $\bar{U}_{2 j}\left(p^{*}, w_{j}, \mathbf{p}_{-j}^{*}, \mathbf{w}_{-j}^{*}\right)>\bar{U}_{2 j}\left(\mathbf{p}^{*}, \mathbf{w}^{*}\right)$. This implies that SMCE is not a Nash equilibrium of the Bertrand-Edgeworth model if $\beta_{2} \gamma>1$.

(ii) $\beta \gamma=1$. In this case, $w^{*} / p^{*}=1$ and there exist infinitely many SMCE, by Proposition 1 . Let us show that $w_{j} / p_{j}=1$ is necessarily a Nash equilibrium strategy for every firm $j \in \mathcal{N}_{2}$.

Take and fix any $j \in \mathcal{N}_{2}$. Since the reservation wage of workers is equal to one, firm $j$ will choose to set $w_{j} / p_{j} \geqslant 1$, for otherwise it cannot attract any labor and would get zero lifetime utility. Let us first suppose that firm $j$ makes $w_{j} / p_{j}>1$ by setting $w_{j}>w^{*}$. In that case, firm $j$ can hire less labor than in SMCE. Hence by producing and consuming less, it obtains smaller lifetime utility. Next suppose $p_{j}<p^{*}$. In this case, firm $j$ will not be better off as was explained in the proof of Proposition 2.

Therefore, unilateral deviation from SMCE is not profitable if and only if $w^{*} / p^{*}$ is equal to one. 